\title{
Knowledge and practice of malaria prevention and management among non-medical students of university of Nigeria, Nsukka
}

\author{
Chigozie Gloria Anene-okeke, Abdulmuminu Isah, Deborah Oyine Aluh*, \\ Amuche Linda Ezeme
}

Department of Clinical Pharmacy and Pharmacy Management, University of Nigeria, Nsukka, Enugu State, Nigeria

Received: 05 December 2017

Revised: 02 January 2018

Accepted: 04 January 2018

\section{*Correspondence:}

Miss. Deborah Oyine Aluh,

E-mail: deborah.aluh@unn.edu.ng

Copyright: (C) the author(s), publisher and licensee Medip Academy. This is an open-access article distributed under the terms of the Creative Commons Attribution Non-Commercial License, which permits unrestricted non-commercial use, distribution, and reproduction in any medium, provided the original work is properly cited.

\begin{abstract}
Background: Inadequate knowledge, misconceptions about the transmission, perception and management of malaria has been reported among various strata of the society and this can adversely affect malaria control measures. This study sought to assess knowledge and prevention practices of malaria among non-medical student in University of Nigeria, Nsukka.

Methods: This was a cross-sectional descriptive study carried out among non-medical students. A simple randomized system was adopted for this study in the selection of the three faculties among the several faculties of non-medical students. A well-structured questionnaire which comprised of both open and close ended questions was adopted and used to elicit information from the students.

Results: A total of 800 consenting UNN students participated in this study Less than one-tenth of the respondents $(5.4 \%, \mathrm{n}=43)$ reported that Plasmodium falciparum is the most common species that causes malaria. More than half of the respondents $(53.5 \%, \mathrm{n}=427)$ had treated mosquito net in their rooms, however only three hundred and thirty eight $(42.3 \%)$ of them reported that they sleep under the mosquito treated net. There was a strong evidence of association between knowledge of malaria and level of academic study $\left(X^{2}=11.01, p=0.015\right)$.

Conclusions: The study results revealed that non-medical students of University of Nigeria Nsukka campus had an appreciable knowledge on prevention and management of malaria which was however, not translated into practice.
\end{abstract}

Keywords: Malaria, Nigeria, Students, Insecticide treated nets, Plasmodium

\section{INTRODUCTION}

Malaria is one of the most common cause of death and illness in children and adults in tropical settings. There were about 212 million new cases of malaria worldwide in $2015 .^{1}$ Ninety percent of the global cases of malaria occur in the African region where Nigeria is located. Malaria is a serious public health challenge in Nigeria where it accounts for more cases and deaths than any other country in the world. ${ }^{2}$ Malaria is a risk for a huge proportion of Nigeria's population. The few people who are unaffected are those who live in the malaria free highlands. ${ }^{3}$ Malaria has been associated with declining quality of life, consultations, treatments, hospitalization and other events related to malaria which often lead to low productivity and lost incomes. ${ }^{3}$

Vector control is the major way to prevent and reduce malaria transmission. In Sub-Saharan Africa, Insecticide Treated Nets (ITNs) have been the cornerstone of malaria prevention efforts. Over the last 5 years, there has been a 
two-fold increase in the use of treated nets in the region. ${ }^{1}$ Indoor residual spraying of insecticides (IRS) has been adopted by national malaria programs in targeted areas. The proportion of the population at risk of malaria protected by IRS declined from a peak of $5.7 \%$ globally in 2010 to $3.1 \%$ in 2015 . $^{1}$ In 2015,106 million people globally were protected by IRS, about half of these people were in Africa.

Many factors have been associated with the spread of malaria such as; environmental changes, malaria vector dynamics, host immune status and individual or community factors such as the socio-economic status, knowledge of malaria and the protective behaviors. ${ }^{4} \mathrm{~A}$ study on knowledge, attitude and management practice on malaria in Anambra State Nigeria, revealed that respondents' knowledge on the cause of malaria included overwork, sunlight and oily food. On the choice of drugs, only $50.9 \%$ used Artemisinin-based Combination Therapies. A significant proportion of the respondents $(40.9 \%)$ made use of the local herb, Azadirachta indica. ${ }^{5}$ Inadequate knowledge, misconceptions about the transmission, perception and management of malaria have been reported among various strata of the society and this has negative effects on malaria control measures. ${ }^{4}$ Recently, there has been growing interest in the role of knowledge, attitudes and screening practices in malaria prevention and control. ${ }^{4,5}$ This study seeks to find out if the media attention and increased awareness of malaria in Nigeria has actually improved the knowledge and attitudes towards Malaria. Thus this study sought to assess knowledge and prevention practices of malaria among non-medical student in University of Nigeria, Nsukka. The results of this study will help determine the extent of emphasis needed on the measures of malaria prevention and management via public enlightenment to reduce occurrence of resistance and rate of mortality.

\section{METHODS}

This was a cross-sectional descriptive study carried out to assess the knowledge and practice of malaria prevention and management among non-medical students of University of Nigeria Nsukka. The study was carried out in three non-medical faculties in University of Nigeria Nsukka: Agricultural sciences, Arts, Social sciences and Education between June 2017 and September 2017. A simple randomized system was adopted for this study in the selection of the three faculties among the several faculties of non-medical students. Collection of data from students in the various departments in the three faculties was done using convenience sampling method. The study was conducted according to the Declaration of Helsinki. Ethical clearance was obtained from the institutional review committee.

A well-structured questionnaire which comprised of both open and close ended questions was adopted from a work by Ibrahim, et al. ${ }^{4}$ The survey questionnaire comprised of three sections which included questions on sociodemographics, knowledge of causes, prevention and management, and practice of malaria prevention and management.

The questionnaire was self-administered to 800 consenting non-medical students. Being knowledgebased research; the students were cautioned to fill the questionnaire immediately. Completed questionnaires were retrieved immediately after completion to avoid sourcing information on internet. The data collected were coded and analyzed using SPSS (Statistical Package for Social Sciences) software package version 16. Descriptive statistics such as frequencies and percentages were used to measure level of knowledge on malaria. Associations between socio-demographic data and knowledge of causes, knowledge of prevention and knowledge of management was done using chi-square. $\mathrm{P}$ values less than or equal to 0.05 showed statistical significance.

\section{RESULTS}

A total of 800 consenting UNN students participated in this study. Four hundred and thirty $(54.5 \%)$ of the student were aged 21-26 years. Five hundred and twenty-two $(65.2 \%)$ of the respondents were female (Table 1).

More than half of the respondents $(66 \%, n=528)$ agreed that malaria is common in the tropical region. Almost all $(95.5 \%, \mathrm{n}=764)$ of the respondent stated that mosquito breeds more during rainy season. Less than one-tenth of the respondents $(5.4 \%, \mathrm{n}=43)$ reported that Plasmodium falciparum is the most common species that causes malaria. Less than one-fifth $(12.4 \%, \mathrm{n}=199)$ of the respondents understood the meaning of malaria prophylaxis (Table 2).

Three-quarters of the respondents surveyed $(75.1 \%$, $\mathrm{n}=599)$ reported presence of bushes around their residence. More than half of the respondent (52.4\%, $\mathrm{n}=291$ ) said they cleared the bushes on weekly basis. More than half of the respondents $(53.5 \%, n=427)$ had treated mosquito net in their rooms, however only three hundred and thirty eight $(42.3 \%)$ of them reported that they sleep under the mosquito treated net. More than half $(58.8 \%, \mathrm{n}=468)$ of the respondents revealed preference of anti-mosquito sprays to sleeping under treated mosquito net (Table 3).

More than a quarter of respondents $(35.1 \%, \mathrm{n}=265)$ revealed no malaria diagnosis in the last months during the time of the study. A good proportion (92.1\%) of the respondents reported ACTs as the most effective antimalaria drugs amongst the ones previously used.

Knowledge of malaria increased with increasing level of academic study. There was a strong evidence of association between knowledge of malaria and level of study $\left(\mathrm{X}^{2}=11.01, \mathrm{p}=0.015\right)$. There was also an association between faculty and knowledge of malaria as students of agricultural science had greater knowledge of malaria than the other two faculties $\left(\mathrm{X}^{2}=4.23, \mathrm{p}=0.000\right)$. 
Table 1: Socio-demographic data of the respondents.

\begin{tabular}{|c|c|c|}
\hline Variables & Frequency & Percentage $(\%)$ \\
\hline \multicolumn{3}{|l|}{ Age of respondent } \\
\hline $15-20$ & 331 & 41.4 \\
\hline $21-26$ & 436 & 54.5 \\
\hline $27-32$ & 32 & 4.0 \\
\hline$\geq 33$ & 1 & 0.1 \\
\hline \multicolumn{3}{|l|}{ Sex of respondents } \\
\hline Male & 278 & 34.8 \\
\hline Female & 522 & 65.2 \\
\hline \multicolumn{3}{|l|}{ Marital status } \\
\hline Single & 756 & 94.5 \\
\hline Married & 36 & 4.5 \\
\hline Engaged & 8 & 1.0 \\
\hline \multicolumn{3}{|l|}{ Academic level } \\
\hline 100 & 237 & 29.6 \\
\hline 200 & 299 & 37.4 \\
\hline 300 level & 141 & 17.6 \\
\hline 400 level & 101 & 12.6 \\
\hline 500 level & 22 & 2.8 \\
\hline \multicolumn{3}{|l|}{ Faculties } \\
\hline Arts & 292 & 36.5 \\
\hline Social science & 294 & 36.8 \\
\hline Agricultural sciences & 214 & 26.8 \\
\hline Total & 800 & 26.7 \\
\hline
\end{tabular}

Table 2: Knowledge of prevention of malaria.

\begin{tabular}{|lll|}
\hline Variables & Frequency & Percentage (\%) \\
\hline Means of transmission of malaria & & 95.5 \\
\hline Mosquito breeds more during rainy season & 764 & 81.2 \\
\hline Type of mosquito that causes malaria? & 650 & 79.4 \\
\hline Malaria parasites belong to the genus plasmodium & 635 & 97.0 \\
\hline Can malaria be prevented? Yes & 776 & 35.4 \\
\hline Methods of prevention known & 625 & 30.4 \\
\hline Use of insecticide treated net & 538 & 16.3 \\
\hline Cleaning the environment & 288 & 4.1 \\
\hline Use of insecticide & 73 & 10.6 \\
\hline Proper covering of the body & 188 & 63.1 \\
\hline Taking anti-malaria drugs & 505 & \\
\hline Have you heard of indoor residual spray before? Yes & & \\
\hline
\end{tabular}

Table 3: Practice of prevention of malaria.

\begin{tabular}{|c|c|c|c|}
\hline \multicolumn{2}{|l|}{ Variables } & Frequency & Percentage $(\%)$ \\
\hline \multicolumn{4}{|l|}{ Practice of malaria prevention } \\
\hline \multirow{3}{*}{ How often do you clear the bushes in your environment? } & Weekly & 291 & 52.4 \\
\hline & Monthly & 213 & 38.4 \\
\hline & Yearly & 51 & 9.2 \\
\hline \multirow{5}{*}{$\begin{array}{l}\text { How often do you drain the stagnant water in your } \\
\text { environment? }\end{array}$} & Weekly & 115 & 34.8 \\
\hline & Monthly & 76 & 23.0 \\
\hline & Yearly & 32 & 9.7 \\
\hline & Never & 17 & 5.2 \\
\hline & Daily & 90 & 27.3 \\
\hline
\end{tabular}




\begin{tabular}{|llll|}
\hline Variables & & Frequency & Percentage (\%) \\
\hline \begin{tabular}{llll|} 
Do you dispose household wastes in an available open space \\
or drainage channel?
\end{tabular} & No & 361 & 45.2 \\
\cline { 2 - 4 } Do you have an insecticide treated net (ITN) in your room? & No & 437 & 54.8 \\
\cline { 2 - 4 } & Yes & 427 & 46.5 \\
\hline \multirow{2}{*}{ Do you sleep under insecticide treated net (ITN)? } & No & 461 & 53.5 \\
\cline { 2 - 4 } & Yes & 338 & 42.3 \\
\hline
\end{tabular}

\section{DISCUSSION}

Most of the respondents in this study were between 21 and 26 years. The age distribution of the respondents in this study was found to share similarity with other Nigerian studies. ${ }^{6,7}$ However, other studies conducted in Ethiopia and Uganda showed variation in age distribution of the participants. ${ }^{8,9}$ The variation in age distribution observed could be attributable to the fact that these studies were community based as against our study which was school based. Most of the respondents in the study were single while the findings of another west African study had more of married subjects as respondents. ${ }^{10}$ This could be attributable to the setting were the studies were conducted since this study was carried out in a tertiary institution where most of them where single as against a community setting with mixed population.

Results from the study revealed that $97 \%$ of the respondents knew that malaria can be prevented. This high knowledge of malaria prevention concurs with findings from similar studies in south western Nigeria. $^{11,12}$ Though three-quarters $(75.1 \%)$ of the respondents admitted to having bushes around their houses, only $52.4 \%$ of them reported that they cleared the bushes weekly. This is a pointer to the need for more intensive public health campaigns on sanitation and hygiene. More than half $(63.1 \%)$ of the respondents knew that IRS is a process of spraying insecticides on the walls inside a home however, only $58.8 \%$ actually used IRS in their homes. This corroborates findings from a similar study among non-medical students in Ondo State, Nigeria. ${ }^{11}$

ITN was the most used method of malaria prevention. More than three-quarters $(78.1 \%)$ knew that ITN was an effective form of Malaria control, however, only $53.5 \%$ actually reported that they used ITN in their homes. The proportion of students who actually slept under ITN in this study is higher than that recorded in other parts of the country. ${ }^{11,13}$ This difference may be attributed to the higher literacy and hence higher knowledge of Malaria preventive practices among the study sample. It may also be due to increased health protection behaviours as a cultural norm among people in Eastern Nigeria. The most common reasons for not using ITN amongst respondents were high cost $(26.4 \%)$ and non-availability $(25.9 \%)$. Spending on malaria prevention, such as bed nets seems to be related to socioeconomic status with better off households allocating a larger share of their income to malaria prevention than poorer households. ${ }^{14}$ This is an indicator to the need for more effective government interventions in making ITN available at affordable prices for vulnerable groups such as pregnant women, children and students.

Findings from our study showed that less than a fifth $(12.4 \%)$ of the students understood malaria prophylaxis to be a preventive treatment for malaria. This concurs with results from a similar study carried out in Oyo state in 2016 but contrasts with findings from a study that was carried out in 2011 where as much as $59 \%$ of the respondents knew about prophylactic malaria drugs and also used them. ${ }^{4,12}$ This lack of understanding may not be unconnected to the fact that malaria prophylaxis is generally not recommended for the general population in Nigeria since it is an endemic region. Thus, emphasis must continually be laid on the use of ITN, environmental sanitation while inappropriate use of chemoprophylaxis must be discouraged.

Our findings also revealed that $64.9 \%$ students reported they had been diagnosed of malaria infection in the past six months. This is similar to a research that reported $65 \%$ of participants had malaria per a year. ${ }^{15}$ However, it is in contrast to a 2016 research which stated that $4.4 \%$ students reported they had been diagnosed malaria infection in the past six months. ${ }^{4}$ This difference may be attributed to the month of data collection in relation to seasons of the year in Nigeria. The mosquitoes breed more in the rainy season and hence the prevalence of Malaria is always higher in the rainy season. Most of the drugs used by the students for the last episodes of malaria were gotten from chemist shops $(30.2 \%)$ and hospital pharmacy $(23.9 \%)$. This is in contrast with similar research studies carried out in other parts of the country and in Tanzania where higher proportions of the respondents visited hospital for the treatment of malaria. ${ }^{4,5,16}$ This reflects the collapse and poor functioning of health care facilities in tertiary institutions such as the one this study took place. There is an urgent need for revitalizing health facilities in tertiary institutions as they should serve as the first point of call for students. During the last diagnosis of malaria, $91.1 \%$ of the students used ACTs mainly artemetherlumenfantrine. This is not surprising as ArtemetherLumefantrine is Nigeria's first line drug for the treatment of uncomplicated Malaria.

There was an evidence of association between faculty and knowledge of malaria. The faculty of agricultural sciences had the highest knowledge level among others which could be due to the science background of the students in this faculty. This study has shown that there 
were gaps in knowledge of malaria etiology, laboratory detection and prophylaxis. This could be due to the fact that majority of the students either have such knowledge gap because they do not have a science-based background or have not given much thoughts to issue of malaria infection, especially as their course curricula do not cover the field. However, this knowledge gaps are worrisome among this educated sample as it gives an idea of bigger knowledge gaps among the general population of 'not-soeducated' Nigerians. Illiterate people and those with low levels of education might be unable to understand written health education materials, such as posters and flyers. ${ }^{17} \mathrm{~A}$ general lack of health information and awareness among poor and marginalized groups can greatly reduce the demand for healthcare services. A good way to win the battle against malaria would be to improve economic levels of populations living in developing countries such as the one where this study took place.

\section{CONCLUSION}

The study results revealed that non-medical students of University of Nigeria Nsukka campus had an appreciable knowledge on prevention and management of malaria which was however, not translated into practice. This therefore demands that effort should be geared towards intensification of malaria public enlightenment programs and promotion of affordable treatment. The use of mass media for disseminating information on prevention, causes and management of malaria among the students should be encouraged.

\section{Funding: No funding sources}

Conflict of interest: None declared

Ethical approval: The study was approved by the Institutional Ethics Committee

\section{REFERENCES}

1. WHO, Fact Sheet. World Malaria Report 2016. Accessed on 5 October 2017.

2. Okonta MJ, Nduka SO, Ilodigwe EE, Anetoh MU. Comparative assessment of two artemisinin based combination therapies in the treatment of uncomplicated malaria among University students in Nigeria. Int J Drug Dev Res. 2013;5(2):211-21.

3. Erhun WO, Agbani EO, Adesanya SO. Malaria prevention: Knowledge, attitude and practice in a south-western Nigerian Community. Afr J Biomed R. 2005;8:25-9.

4. Ibrahim A, Oluberu OA, Usman SO, AkintayoUsman NO, Isola IN, Ojediran TE, et al. Oyo State Students and Malaria Management. Turkish J Fam Med Prim Care. 2016;10(3):126-30.

5. Iwueze MO, Ezugbo-Nwobi IK, Umeanaeto PU, Egbuche CM, Anaso CI. Knowledge, attitude and management practices on malaria: A case study of Amansea Awka North Local Government Area of
Anambra State, Nigeria. The Bioscientist. 2013;1(1):32-8.

6. Skeet J. Malaria: Its Causes, Treatment and Methods of Prevention. Nurs Times. 2005;101(20):43-5.

7. Danjuma BA, Tolulope AO, Zuwaira HI, Olatunde YK, Olufemi AE, Egga, et al. Knowledge and practice of methods of malaria prevention among nursing and midwifery students in Plateau state North Central Nigeria. Int $\mathbf{J}$ Biomed Res. 2017;8(04):215-9.

8. Nwanje LF. Knowledge, attitude and practices of malaria prevention and control in Uganda. A case study of Nsaabwa village in Mukono District. January 2013. Available AT: http://www.musphcdc. ac.ug/files/pdf. Accessed on 2 December 2016..

9. Yared L, Ayaleuw T, Tefera B, Kora T. Knowledge, attitude and practice of malaria prevention in urban areas of Assosa Zone Western Ethiopia. Ethiopia J. Health Dev. 2007;21(2):157-65.

10. Kimbi HK, Nkesa SB, Nduamukong-Nyanga JL, Sumbele IU, Atashili J, Atang MBA. Knowledge and perceptions towards malaria among vulnerable groups in the Buea Health District, Cameroon. BMC Public Health. 2014; 14:883.

11. Saheed OU, Temitope OI, Ayooluwa SA, Tonubari F, Oluwakemi, Edet-Utan, et al. knowledge and practice of malaria prevention among non-medical students of higher institution in Ondo State,Nigeria. Int J Innov Med Edu Res. 2015;1:15-9.

12. Adegun JA, Adegboyega JA, Awosusi AO. Knowledge and the preventive strategies of malaria among migrant farmers in Ado Ekiti Local Government Area, Nigeria. Am J Sci Industr Res. 2011;2(6):883-9.

13. Udonwa NE, Gyuse N, Etokidem AJ. Malaria: Knowledge and prevention practices among school adolescents in a coastal community in Calabar, Nigeria. Afr J Prm Health Care Fam Med. 2010;2(1):4.

14. Ettling MB. Economic impact of malaria in Malawian households. Tropical Medicine and Parasitology. 1994;45(1):74-9.

15. Sam-Wobo SO, Akinboroye T, Anosike JC, Adewale B. Knowledge and practices on malaria treatment measures among pregnant women in Abeokuta, Nigeria. Tanzan J Health Res 2008;10(4):226-31.

16. Mazigo HD, Obasy E, Mauka W, Manyiri P, Zinga M, Kweka HJ, et al. Knowledge, attitudes and practices about malaria abd its control in Rural Northwest Tanzania. Malar Res Treat 2010:794261.

17. Ricci F. Social implications of Malaria and their relationships with poverty. Mediterranean $\mathbf{J}$ Haematol Infect Dis. 2012;4(1):e2012048.

Cite this article as: Anene-okeke CG, Isah A, Aluh DO, Ezeme AL. Knowledge and practice of malaria prevention and management among non-medical students of university of Nigeria, Nsukka. Int $\mathbf{J}$ Community Med Public Health 2018;5:461-5. 